\title{
Interaction of fas and fas ligand in a rat $36 b 10$ glioma model
}

\author{
Timothy Ryken, M.D., Bruce Frankel, M.D., Sharon Longo, B.A., \\ and Zita Sibenaller, Ph.D. \\ Division of Neurosurgery, University of Iowa Hospitals and Clinics, Iowa City, Iowa; and Department \\ of Neurosurgery, University Hospital, SUNY HSC, Syracuse, New York
}

\begin{abstract}
Object. An experimental model of the fas and fas ligand (fasL) interaction in malignant glioma was developed. Methods. Using plasmid-based delivery, 36B10 rat glioma cells were modified to express fas (36B10-fas), and a delivery fibroblast cell line was modified to produce fasL, resulting in the FR-fasL cell line. Evaluation of fas expression was performed with flow cytometry and expression of fasL confirmed by Western blot analysis. Once the cell lines were created and partially characterized, fas-induced cytotoxicity was evaluated using an antibody-mediated assay for 36B10-fas that demonstrated significant toxicity at 24 and 48 hours. To evaluate the potential for activating the fas molecule by using cell-mediated delivery, coculture cytotoxicity studies were performed with a target cell line (36B10-fas) and effector cell line (FR-fasL). Using a series of culture ratios, increasing cytotoxicity was noted, suggesting that activation of the transfected fas receptor by fasL expression on the carrier cell was occurring.

Conclusion. Based on their experiments, the authors describe a model for evaluating the interaction of fas and fasL in a cellular model of malignant glioma.
\end{abstract}

KeY WORDS • glioma $・$ fas $・$ fas ligand $・$ cytotoxicity $・$ gene transfer

FAS is a type I membrane protein that mediates the induction of apoptosis in selected cells when ligated either by an anti-fas antibody or by interaction with fasL., 2,6,10,23 Fas is a member of the TNF/nerve growth factor receptor superfamily. ${ }^{33,34}$ Fas ligand is a membrane-type cytokine belonging to the TNF family and is expressed in T cells activated by various factors including interleukin 2 , phorbol myrisate acetate, and anti-CD3..$^{24,30,31}$ The fas/fasL pathway has been shown to play a role in T cell-mediated cytotoxicity. ${ }^{25}$

The role of apoptosis, or programmed cell death, in the development of CNS neoplasia has received increasing interest as techniques for studying the signaling pathways and genetics of this process have been developed. $15,16,28,36$, $39,42,48$ The mechanism of apoptotic cell death is complex. It involves receptor-mediated protease activation, cytolytic plasma protein interactions, and ultimately distinct morphological alterations. These alterations can be observed microscopically and include DNA degradation and margination, condensation of chromatin, cell membrane alter-

Abbreviations used in this paper: $\mathrm{CDNA}=$ complementary DNA; $\mathrm{CNS}=$ central nervous system; fasL $=$ fas ligand; FR-fasL = fibroblast cell line modified to produce fasL; MTT = methylthiotetrazole; $\mathrm{TNF}=$ tumor necrosis factor. ations and the formation of apoptotic cascade. Research specifically focused on apoptosis and CNS neoplasia has included interaction of $p 53$ with the retinoblastoma gene and TNF-alpha, the identification of apoptosis-protective genes in glioma, and upregulation of protease enzymes important to the apoptotic cascade..$^{18-21,35}$ A recent description of the interaction of fas-induced apoptosis with transforming growth factor-beta suggests the central role of these interactions in the modulation of the cell cycle. ${ }^{1} \mathrm{In}$ a series of studies, Weller, et al., ${ }^{44-47}$ have examined fas-induced cytotoxicity in a series of human glioma explants. They have shown, under selective conditions, that apoptosis can be induced when ligated by an anti-fas antibody.

Given the increasing evidence that apoptosis may play a role either in the induction or propagation of neoplastic transformation, we undertook to develop a model in which to examine fas/fasL interaction in glioma cells. In this report we describe the development of a plasmid-based delivery system for fas and fasL that allows the interaction of these molecules to be examined in malignant glial tissue. Because antibodies to these molecules are available, they can be assayed in a semiquantitative fashion to determine expression, and assays for cytotoxicity allow the effect of their interaction to be determined. ${ }^{3,4,27}$ Because of the complexity of the apoptotic cascade and the multifac- 
torial events involved in neoplastic transformation, it is unlikely that any single system will allow these cells to be eliminated. ${ }^{7}$ However, additional examination of the fas and fasL system and other interactions in the apoptotic cascade will provide insight into the steps involved in the maintenance and control of cellular proliferation.

\section{MATERIALS AND METHODS}

\section{Cell Lines and Primary Cultures}

All cells were maintained in Dulbecco's modified Eagle's medium, supplemented with $10 \%$ heat-inactivated fetal bovine serum, $50 \mathrm{U} / \mathrm{ml}$ penicillin, $50 \mathrm{mg} / \mathrm{ml}$ streptomycin, $2 \mathrm{mmol} / \mathrm{L}$ L-glutamine, $0.1 \mathrm{mmol} / \mathrm{L}$ nonessential amino acids, and $10 \mathrm{mmol} / \mathrm{L}$ HEPES, $\mathrm{pH}$ 7.2. The 36B10 rat glioma cell line was used for transfection and cytotoxicity studies as described later. ${ }^{40}$ These cells were assayed for fas expression by using flow cytometry. We used the Yac-1 (mouse lymphoma) and fibroblast (Sprague-Dawley rat fibroblast) cell lines. The Yac-1 cell line was used as a positive control for mouse fas expression. ${ }^{29}$

Plasmid Construction. In a plasmid containing cDNA for rat fasL in pBlue Script, the $1.6-\mathrm{Kb}$ fragment containing the fasL cDNA was excised using XhoI and religated into the multiple cloning site of pcDNA3.1/zeo, creating pcDNA3.1zeo-fasL. Orientation was confirmed by restriction digest and appropriate clones expanded. The fas (murine)-containing plasmid was used as previously described. ${ }^{43}$

Cell Transfection. The 36B10 glioma cells were propagated and $5 \times 10^{4}$ cells were selected for transfection. The fas plasmid $(30 \mu \mathrm{g})$ was introduced into the target cells by using calcium precipitation, and positive clones were selected for neomycin resistance by using $500 \mu \mathrm{g} / \mathrm{ml}$ G418 (36B10-fas). Rat fibroblasts were propagated and 2 $\times 10^{5}$ were transfected with $2 \mu \mathrm{g}$ pcDNA3.1zeo-fasL by using 5 and $10 \mu \mathrm{l}$ of Lipofectin; positive clones were selected for zeocin resistance $(400 \mu \mathrm{g} / \mathrm{ml})$. For a negative control cell line fibroblast was transfected with $2 \mu \mathrm{g}$ pcDNA3.1zeo by using Lipofectin.

Flow Cytometry. A total of $10^{6} 36 \mathrm{~B} 10,36 \mathrm{~B} 10$-fas, and Yac-1 cells (positive control) were incubated with $5 \mu \mathrm{g} / \mathrm{ml}$ biotinylated anti-mouse fas monoclonal antibody, washed, and reincubated with streptavidin-conjugated FITC (1:100). All samples were incubated with their appropriate isotype controls and then analyzed using a FACScan flow cytometer on a logarithmic scale at $488 \mathrm{~nm}$.

Western Blot Analysis. The expression of fasL in the line FR-fasL was evaluated by sodium dodecyl sulfatepolyacrylamide gel electrophoresis and Western blot analysis. Briefly, total protein from serum-free supernatent $(0.5 \mathrm{ml})$ obtained from FR-fasL cultures was precipitated with acetone and then electrophoresed on a $12 \%$ sodium dodecyl sulfate polyacrylamide gel, transferred to nitrocellulose, and immunostained with polyclonal rabbit anti-fasL antibody $(2 \mu \mathrm{g} / \mathrm{ml})$. The resultant protein band was reacted with biotinylated anti-rabbit (1:500), followed by serum albumin-horseradish peroxidase for detection. Kaleidoscope molecular-weight markers were used to estimate sizes.

\section{Cytotoxicity Assays}

Antibody-Mediated Toxicity. Transfected 36B10-fas rat glioma, 36B10 cells, and Yac-1 cells were plated into 96-well tissue culture plates at a cell density of $1 \times 10^{4}$ cells/well in a total volume of $50 \mu \mathrm{l}$ and incubated overnight at $37^{\circ} \mathrm{C}$. Anti-mouse Fas was added to cells in concentrations ranging from 0.01 to $10 \mu \mathrm{g} / \mathrm{ml}$ for 24 and 48 hours in the presence of $1 \mu \mathrm{g} / \mathrm{ml}$ cyclohexamide as previously described. ${ }^{14,45}$ After indicated times, the wells were assayed for cell viability by using an MTT assay as previously described. ${ }^{40}$

Effector/Target Toxicity. Cocultures of target cells (36B10, 36B10fas, and Yac-1) and FR-fasL were assayed for cytotoxicity. Target cells were plated into 96-well round-bottom plates at $5 \times 10^{3}$ cells/well. Into the same wells, effector cells were plated to achieve final effector/target ratios of $0.25,1.0,5.0$, and 10.0. The cocultures were incubated for 24 hours at $37^{\circ} \mathrm{C}$ and assayed for cytotoxicity by using an MTT assay as noted in the preceding section. The percentage of cytotoxicity was calculated by obtaining the absorbance value at $550 \mathrm{~nm}$ from the MTT assay for each condition by using the following formula: $(1-[\{$ Effectors + Targets $\}-\{$ Effectors $\}] /$ Targets) $\times 100 .{ }^{17}$

\section{SOURCES OF SUPPLIES AND EQUIPMENT}

We obtained the Dulbecco's modified Eagle's medium, HEPES, and Lipofectin from Gibco BRL (Grand Island, NY). The fetal bovine serum was purchased from Sigma (St. Louis, MO). A. Spence (University of Seattle, Seattle, WA) kindly provided the rat glioma cell line, and S. Nagata (Osaka Bioscience Institute, Osaka, Japan) kindly provided the cDNA-containing plasmid. The Yac-1 and fibroblast cell lines were obtained from American Tissue Type Collection (Rockville, MD). We acquired the pcDNA3.1zeo from Invitrogen (San Diego, CA). The fas (murine)-containing plasmid came from the laboratory of P. Goldstein (Centre d'immunologie de MarseilleLuminy, France). The calcium precipitation, used to introduce the fas plasmid to the target cells, is produced by Stratagene (La Jolla, CA). Pharmigen (San Diego, CA) manufactures the anti-mouse fas monoclonal antibody and the anti-mouse (Jo2).

The streptavidin-conjugated FITC and the FACScan flow cytometer were purchased from Becton-Dickinson (Franklin Lakes, NJ). We obtained the polyclonal rabbit anti-fasL antibody from Santa Cruz Biotech (Santa Cruz, CA); the SA-HPP from Biogenex (San Ramon, CA); and the kaleidoscope molecular-weight markers from BioRad (Rockville, NY).

\section{RESULTS}

\section{Cell Preparation and Confirmatory Studies}

The plasmid construction and cell transfection were performed using standard techniques. To analyze the 36B10 glioma cell line for fas-expression before and after transfection with a fas-containing plasmid, we used fluorescent-activated flow cytometry. As seen in Fig. 1, prior to transfection, the $36 \mathrm{~B} 10$ cell line did not appear to 


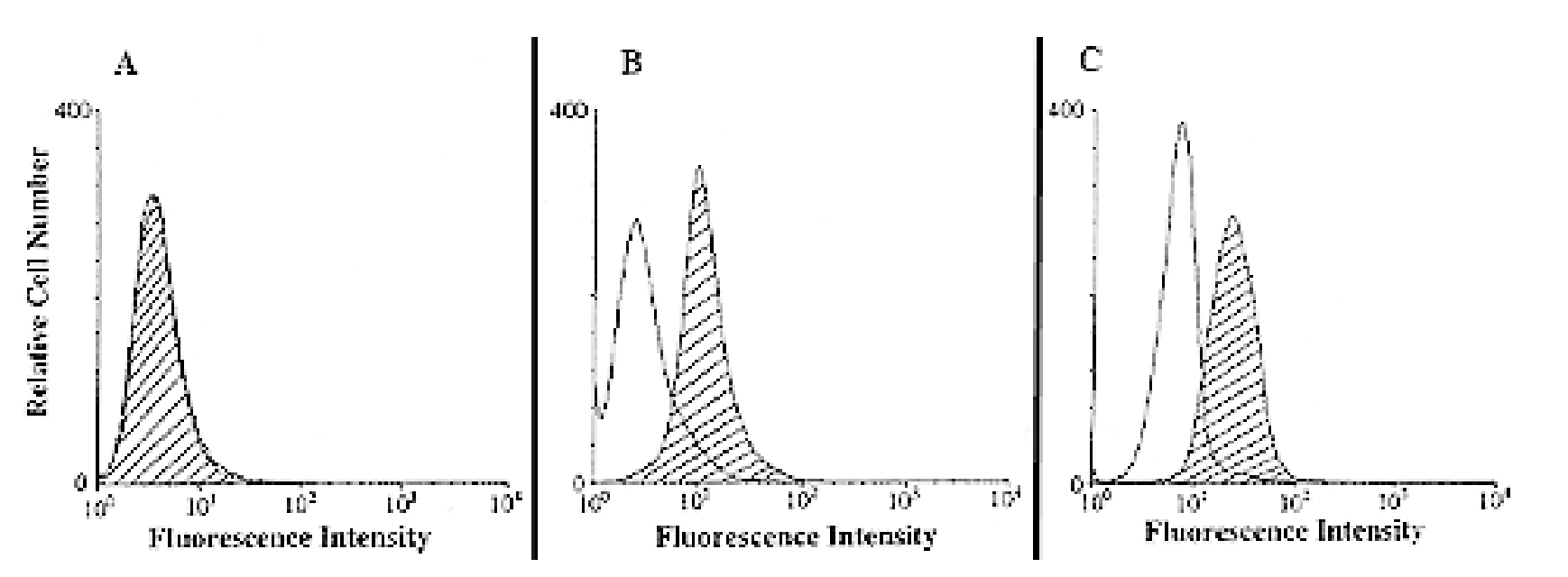

Fig. 1. Graphs showing the results of flow cytometry of 36B10 (left), 36B10-fas (center) and Yac-1 (right) cells. Each cell culture was incubated with anti-fas antibody and sorted using fluorescent-activated cell sorting analysis. The second peak indicates cells that have been labeled with the anti-fas antibody. In the case of 36B10-fas, this indicates successful cell transfection. The Yac-1 cells (known to express fas) serve as a positive control.

express a significant amount of fas. Following transfection, the second peak depicted in Fig. 1 indicates the occurrence of binding with the anti-fas antibody in a significant number of cells; the Yac-1 cell line serves as a positive control.

The expression of fasL was confirmed in the line FRfasL by using Western blot analysis. Staining with antifasL antibody resulted in a band at approximately $40 \mathrm{kD}$ as expected.

\section{Antibody-Induced Cytotoxicity}

Incubation of the target cell line with increasing amounts of anti-fas antibody resulted in cytotoxic effects, presumably caused by activation of the fas receptor complex (Fig. 2). At the 24- and 48-hour intervals, significant cytotoxicity was observed even at the lowest anti-fas antibody concentrations tested $(\mathrm{p}<0.01$, two-tailed t test). These studies confirmed that altered sensitivity to fasinduced cytotoxicity resulted from transfection of the 36B10 (fas-negative) cell line by transfection with the fascontaining plasmid.

\section{Coculture Results}

To determine whether a cellular delivery source of a fas-activating molecule could elicit a biological effect on the fas-expressing target cell (site-specific delivery), we used a coculture model of target (36B10-fas) and FR-fasL. By using increasing ratios of fasL-expressing cells, we were able to demonstrate increased cytotoxicity in the cocultures (Fig. 3). The increase in cytotoxicity reached statistical significance at an effector/target ratio of 1.0 $(\mathrm{p}=0.0001$, two-tailed $\mathrm{t}$ test $)$ and was clearly significant at the higher ratios of $5.0(\mathrm{p}<0.0001)$ and $10.0(\mathrm{p}<$ 0.0001 ). The Yac-1 cells served as positive controls and were clearly even more sensitive to fas activation.

\section{DISCUSSION}

Interest in the fas and fasL interaction, including the effect on cellular immunology and induction of apoptotic cell death, has increased since first described. ${ }^{12}$ The fas and fasL system has been postulated to play an important role in how tumor cells evade immune surveillance, and it
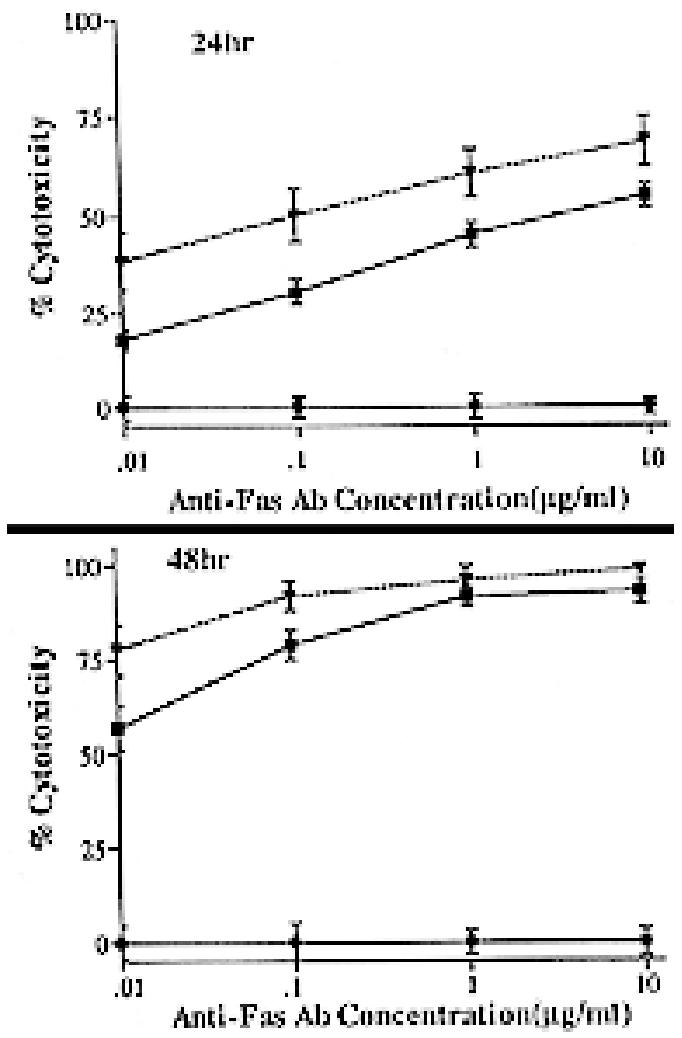

Fig. 2. Graphs indicating the presence of anti-fas antibodyinduced cytotoxicity. The 36B10- (circles) and 36B10-fas-containing cells (squares) were incubated with increasing concentrations of anti-fas antibody to elicit activation of the fas receptor. Significant toxicity was observed at all concentrations tested at both 24 (upper) and 48 hours (lower). The Yac-1 cells (triangles) served as a positive control. 


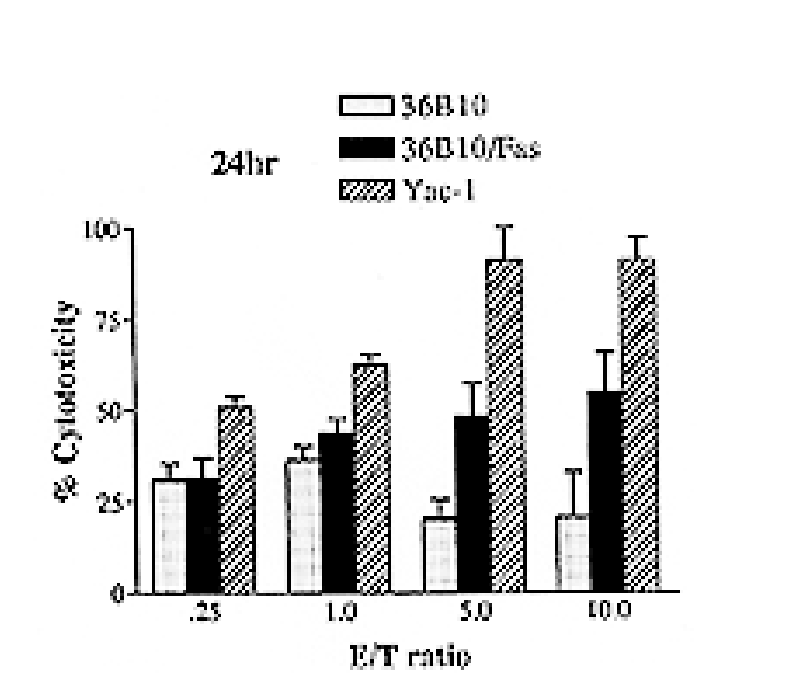

Fig. 3. Bar graph showing results of coculture of 36B10-fas and FR-fasL. Cytotoxicity studies were undertaken using increasing ratios of effector (fasL expressing) to target (36B10-fas) cells. The resultant increase in cytotoxicity is attributed to increased activation of the transfected fas receptors on the 36B10-fas cells. The higher cytotoxicity observed in the Yac-1 cells suggests that increasing expression of fas should result in an increased biological effect.

has been proposed as a mechanism by which apoptosis in neoplastic tissues is induced and controlled., ${ }^{9,32,42}$ Analysis of our data suggests that fas and fasL can be upregulated and that cytotoxicity can be induced in target cells by activation of the fas receptor.

We were able to demonstrate upregulation of both molecules in the transfected cells and were able to induce cytotoxicity in the target cell line with antibody and ligand activation of fas. The findings in this study confirm those reported by Weller, et al., ${ }^{44}{ }^{46}$ and others ${ }^{30}$, suggesting that fas can be upregulated and potentially used as a target for cell-specific therapy.

This type of approach, in which genetic material is introduced into the cellular genome in an attempt to elicit a specific effect, is an example of "genetic therapeutics," as opposed to the more common term "gene therapy" in which it is implied that, in some fashion, a faulty genome is being repaired or replaced. Transfection with the fascontaining plasmid is not an attempt to correct a known defect in the genome but, rather, takes advantage of a known biological effect when a specific receptor is activated. ${ }^{7}$

Expression of fas in the normal adult CNS appears to be restricted to endothelial cells; however, there is increasing evidence that fas is expressed in glial tumors and that it is present in amounts corresponding roughly with their biological behavior. ${ }^{8,11,38}$ Expression of the fasL, first described in activated $\mathrm{T}$ lymphocytes, has been demonstrated in certain epithelial tissues including neurons and the Sertoli's cells of the testes. ${ }^{49}$ It has also been demonstrated in malignant cells including those found in melanoma, breast carcinoma, and glial-derived tumors. ${ }^{13,26}$ Whether the presence of fas and fasL in glial tumors represents simply an indication of increased apoptosis in a tissue undergoing rapid cell growth or whether their presence indicates an intrinsic defect in normal cell metabolism and turnover is unknown. In our laboratory and those of oth-

\section{T. Ryken, et al.}

ers the coexpression of both of these factors on the same type of malignant glial cell has been demonstrated, and the level of expression appears to correspond with the biological behavior of the tumor. ${ }^{5,8,11}$ The biological advantage conferred on the cell, by the expression of both factors simultaneously, is unknown but suggests an important role for apoptosis and immunoregulation in the progression of malignant glioma. There may also be a critical balance of fas and fasL expression that is disrupted in the progression to the neoplastic state, as is believed to occur in other apoptotic-immunomodulating systems. $22,37,41$

The present line of research was undertaken to develop a model in which the expression and interaction of fas and fasL could be examined in transformed glia. In this study, plasmid-based delivery with constructs containing fas and fasL were used to upregulate expression of these molecules in selected cell lines (36B10-fas and FR-fasL). Successful transformation was confirmed using Western blot analysis for the FR-fasL line. Both transfection and biological activity of the 36B10 fas rat glioma line was confirmed by performing flow cytometry and by an antibodyinduced cytotoxicity assay. To begin the assessment of the interaction between fas and fasL in this model, we cocultured the fas-expressing target cells (36B10 fas) with the fasL-expressing cells FR-fasL in a cytotoxicity assay. In terms of the different ratios of cells, our results suggest an effect of the fasL-expressing cells on the fas-containing target cell population. Controlling the level of both fas and fasL expression should allow the following question to be addressed: how important is the amount of expression in determining the resultant biological effect?

This study was designed to create a model to study the intereaction of fas and fasL. We have attempted to begin to characterize this interaction; however, many interesting questions remain unanswered at this time. Given time, we believe this model will greatly facilitate the understanding of the interaction of these molecules.

A major challenge in the use of genetic-based therapy remains the technique of delivery to the target tissue. The use of viral-based therapies in the treatment of glioma continues to be actively investigated, and retroviral and adenoviral fas and fasL vectors are available. We used plasmids because for transfection because of their ease of construction and delivery in the in vitro model. Plasmid delivery is possible in vivo by using lipofection or particle-based delivery systems. Selection of the most appropriate method of delivery will depend on further study. Important considerations are the volume and distribution of tissue required to be transfected, the duration of transgene expression required, and the immune response induced by the expression of foreign molecules in the target tissue. We believe the current results warrant additional study in which the interaction of fas and fasL in malignant glioma is evaluated, and we propose that cell-mediated delivery of fasL may be a feasible technique by which to activate fas and initiate the resultant apoptotic cascade.

\section{References}

1. Ashley DM, Kong FM, Bigner DD, et al: Endogenous expression of transforming growth factor beta- 1 inhibits growth and 
tumorigenicity and enhances fas-mediated apoptosis in a murine high grade glioma model. Cancer Res 58:302-309, 1998

2. Debatin KM, Beltinger C, Bohler T, et al: Regulation of apoptosis through CD95 (APO-I/Fas) receptor-ligand interaction. Biochem Soc Trans 25:405-410, 1997

3. DiGiuseppe JA, LeBeau P, Augenbraun J, et al: Multiparameter flow-cytometric analysis of bcl-2 and Fas expression in normal and neoplastic hematopoiesis. Am J Clin Pathol 106:345-351, 1996

4. Fadeel B, Thorpe CJ, Yonehara S, et al: Anti-Fas IgG1 antibodies recognizing the same epitope of Fas/APO-1 mediate different biological effects in vitro. Int Immunol 9:201-209, 1997

5. Frankel B, Julien T, Marsh S, et al: Fas and Fas ligand in malignant glioma: expression and genetic transfer. Soc Neurosci Abstr 23:2444, 1997 (Abstract)

6. Freiberg RA, Spencer DM, Choate KA, et al: Fas signal transduction triggers either proliferation or apoptosis in human fibroblasts. J Invest Dermatol 108:215-219, 1997

7. Gordon JW: The daunting challenges of gene therapy for malignant disease. Hepatology 23:1696-1697, 1996

8. Gratas C, Tohma Y, Van Meir EG, et al: Fas ligand expression in glioblastoma cell lines and primary astrocytic brain tumors. Brain Pathol 7:863-869, 1997

9. Griffith TS, Ferguson TA: The role of FasL-induced apoptosis in immune privilege. Immunol Today 18:240-244, 1997

10. Gulbins E, Szabo I, Lang F: Physiology of Fas-induced programmed cell death. Cell Physiol Biochem 6:361-375, 1996

11. Hussain N, Chiocca EA, Rainov N, et al: Co-expression of Fas and Fas Ligand in malignant glial tumors and cell lines. Acta Neuropathol 95:287-290, 1998

12. Itoh N, Nagata S: A novel protein domain required for apoptosis. Mutational analysis of human Fas antigen. J Biol Chem 268:10932-10937, 1993

13. Keane MM, Ettenberg SA, Lowrey GA: Fas expression and function in normal and malignant breast cell lines. Cancer Res 56:4791-4798, 1996

14. Kimura K, Yamamoto M: Rapid induction of fas antigen mRNA expression in vivo by cycloheximide. Cell Biochem Funct 15:81-86, 1997

15. Lau HT, Stoeckert CJ: FasL_- too much of a good thing? Transplanted grafts of pancreatic islet cells engineered to express Fas ligand are destroyed not protected by the immune system. Nat Med 3:727-728, 1997

16. Manfredi AA, Rovere P, Heltai S, et al: Fas, apoptosis and the cell cycle. Immunol Today 17:345-346, 1996

17. Martinez-Lorenzo MJ, Alava MA, Anel A, et al: Release of preformed Fas ligand in soluble form is the major factor for actiation-induced death of Jurkat T cells. Immunology 89:511-517, 1996

18. Micheau O, Solary E, Hammann A, et al: Sensitization of cancer cells treated with cytotoxic drugs to fas-mediated cytotoxicity. J Natl Cancer Inst 89:783-789, 1997

19. Mizuno M, Yoshida J: Tumor necrosis factor-a gene transfer augments anti-fas antibody-mediated apoptosis in human glioma cells. Jpn J Cancer Res 87:543-547, 1996

20. Muller M, Strand S, Hug H, et al: Drug-induced apoptosis in hepatoma cells is mediated by the CD95 (APO-1/Fas) receptor/ligand system and involves activation of wild-type p53. J Clin Invest 99:403-413, 1997

21. Muruve D, Nicolson AG, Manfro RC, et al: Adenovirus-mediated expression of Fas ligand induces hepatic apoptosis after systemic administration and apoptosis of ex vivo-infected pancreatic islet allografts and isografts. Hum Gene Ther 8: 955-963, 1997

22. Mustonen M, Raunio H, Paakko P, et al: The extent of apoptosis is inversely associated with bcl-2 expression in premalignant and malignant breast lesions. Histopathology 31:347-354, 1997
23. Nagata S: Apoptosis: telling cells their time is up. Curr Biol 6: 1241-1243, 1996

24. Nagata S: Fas ligand and immune evasion. Nat Med 2: 1306-1307, 1996

25. Nakajima H, Oka T: Analysis of biochemical and biological functions of Fas-ligand (FasL) and Fas on activated T cells in allo-immune response. Transplant Proc 29:1096-1100, 1997

26. Niehans GA, Brunner T, Frizelle SP, et al: Human lung carcinomas express Fas ligand. Cancer Res 57:1007-1012, 1997

27. Ohta S, Mizuno M, Takaoka T, et al: Augmentation of anti-Fas antibody-mediated apoptosis on human glioma cells by liposomes associated with the antibody. J Neurooncol 35:7-11, 1997

28. Reap EA, Roof K, Mayno K, et al: Radiation and stress-induced apoptosis: a role for Fas/Fas ligand interactions. Proc Natl Acad Sci USA 94:5750-5755, 1997

29. Rensing-Ehl A, Frei K, Flury R, et al: Local Fas/APO-1 (CD95) ligand-mediated tumor cell killing in vivo. Eur J Immunol 25:2253-2258, 1995

30. Roth W, Fontana A, Trepel M: Immunochemotherapy of malignant glioma: synergistic activity of CD95 ligand and chemotherapeutics. Cancer Immunol Immunother 44:55-63 1997

31. Rudert F, Wang Y, Lindridge E, et al: Apoptosis through CD95 (Fas/APO-1), but not a CD40/CD95 chimeric receptor, is inhibited by phorbol-12-myristate-13-acetate. DNA Cell Biol 16: 197-205, 1997

32. Saas P, Walker PR, Hahne M, et al: Fas ligand expression by astrocytoma in vivo: maintaining immune privilege in the brain? J Clin Invest 99:1173-1178, 1997

33. Schlottmann, K, Coggeshall KM: CD95/Fas/Apo-1-mediated signal transduction. Cell Physiol Biochem 6:345-360, 1996

34. Schneider P, Bodmer JL, Holler N, et al: Characterization of Fas (Apo-1, CD95)-Fas ligand interaction. J Biol Chem 272: 18827-18833, 1997

35. Sheard MA, Vojtesek B, Janakova L, et al: Up-regulation of fas (CD95) in human p53wild-type cancer cells treated with ionizing radiation. Int J Cancer 73:757-762, 1997

36. Shimizu M, Yoshimoto T, Nagata S, et al: A trial to kill tumor cells through Fas (CD95)-mediated apoptosis in vivo. Biochem Biophys Res Commun 228:375-379, 1996

37. St. Clair EG, Anderson SJ, Oltvai ZN: Bcl-2 counters apoptosis by Bax heterodimerization-dependent and -independent mechanisms in the T-cell lineage. J Biol Chem 272:29347-29355, 1997

38. Tachibana O, Lampe J, Kleihues P, et al: Preferential expression of Fas/APO1 (CD95) and apoptotic cell death in perinecrotic cells of glioblastoma multiforme. Acta Neuropathol 92:431-434, 1996

39. Tanaka M, Suda T, Haze K, et al: Fas ligand in human serum. Nat Med 2:317-322, 1996

40. Traynelis VC, Ryken TC, Cornelius AS: Cytotoxicity of cisparinaric acid in cultured malignant gliomas. Neurosurgery 37:484-489, 1995

41. Van der Vliet HJJ, Wever PC, Van Diepen FNJ: Quantification of $\mathrm{Bax} / \mathrm{Bcl}-2$ ratios in peripheral blood lymphocytes, monocytes and granulocytes and their relation to susceptibility to anti-Fas (anti-CD95)-induced apoptosis. Clin Exp Immunol 110:324-328, 1997

42. Walker PR, Saas P, Dietrich PY: Role of Fas ligand (CD95L) in immune escape: the tumor cell strikes back-commentary. J Immunol 158:4521-4524, 1997

43. Watanabe-Fukunaga R, Brannan CI, Itoh N, et al: The cDNA structure, expression, and chromasomal assignment of the mouse Fas antigen. J Immunol 148:1274-1279, 1992

44. Weller M: Genetic regulation and therapeutic modulation of 
apoptosis in human malignant glioma. Cell Physiol Biochem 6:376-380, 1996

45. Welle M, Frei K, Groscurth P, et al: Anti-fas/APO1 antibodymediated apoptosis of cultured human glioma cells. J Clin Invest 94:954-964, 1994

46. Weller M, Kleihues P, Dichgans J, et al: CD95 ligand: lethal weapon against malignant glioma? Brain Pathol 8:285-293, 1998

47. Weller M, Weinstock C, Will C, et al: CD95-dependent T-cell killing by glioma cells expressing CD95 ligand: more on tumor immune escape, the CD95 counterattack, and the immune privilege of the brain. Cell Physiol Biochem 7:282-288, 1997

48. Yano H, Fukuda K, Haramaki M, et al: Expression of Fas and anti-Fas-mediated apoptosis in human hepatocellular carcinoma cell lines. J Hepatol 25:454-464, 1996
49. Xerri L, Devilard E, Hassoun J, et al: Fas ligand is not only expressed in immune privileged human organs but is also coexpressed with Fas in various epithelial tissues. Mol Pathol 50: 87-91, 1997

Manuscript received February 15, 2000.

Accepted in final form April 3, 2000.

This work was supported in part by the American Association of Neurological Surgeons VanWagenen Fellowship and the Robert and Molly King Endowed Chair in Neuroscience.

Address reprint requests to: Timothy Ryken, M.D., Division of Neurosurgery, University of Iowa Hospitals and Clinics, 200 Hawkins Drive, Iowa City, Iowa 52242. email: timothy-ryken@ uiowa.edu. 